\title{
Association of body mass index, sagittal abdominal diameter and waist-hip ratio with cardiometabolic risk factors and adipocytokines in Arab children and adolescents
}

Omar S Al-Attas ${ }^{1,2^{*}}$, Nasser M Al-Daghri, ${ }^{1,2}$, Majed S Alokail ${ }^{1,2}$, Khalid M Alkharfy ${ }^{1,3}$, Hossam Draz ${ }^{1,4}$, Sobhy Yakout ${ }^{1}$, Shaun Sabico ${ }^{1}$ and George Chrousos, ${ }^{1,5}$

\begin{abstract}
Background: Sagittal abdominal diameter (SAD) is a novel anthropometric measure hypothesized to be a surrogate measure of visceral abdominal obesity in adults. This study aims to determine whether SAD is superior to other anthropometric measures such as body mass index (BMI) and waist to hip ratio (WHR) in terms of association to cardiometabolic risk and circulating adipocytokine concentrations in a cohort of Saudi children and adolescents.

Methods: A total of 948 (495 boys and 453 girls) apparently healthy children with varying BMl, aged 10-17 years, were included in this cross sectional study. Fasting glucose, lipid profile, leptin, adiponectin, resistin, insulin, TNF- $a$ and aPAl-1 were measured in serum and HOMA-IR was calculated. MetS components were defined according to the International Diabetes Federation (IDF) criteria.

Results: BMI was superior to SAD as well as WHR, and had the highest number of significant associations to MetS components and adipocytokines even after adjustment for age and gender, including blood pressure, lipids, glucose and leptin.

Conclusion: In conclusion, while SAD is significantly associated with components of MetS among children and adolescents, it is not superior to BMI. The use of SAD therefore may not be practical for use in the pediatric clinical setting. Follow-up studies are needed to determine whether SAD has clinical significance in terms of harder outcomes such as predicting diabetes mellitus or cardiovascular diseases.
\end{abstract}

Keywords: Sagittal abdominal diameter, Insulin resistance, Adipocytokines, Arab children

\section{Background}

Obesity confers increased risk for cardiovascular diseases as a result of accumulation of visceral fat, which alters intermediary metabolism and insulin sensitivity of peripheral tissues [1-5]. Conventionally, waist circumference is used in both clinical practice and biomedical research to measure abdominal obesity and to screen for the presence of the metabolic syndrome (MetS). Other anthropometric indices, such as body mass index (BMI), as

\footnotetext{
* Correspondence: omrattas@ksu.edu.sa

'Biomarkers Research Program, Biochemistry Department, College of Science, King Saud University, Riyadh 11451, Kingdom of Saudi Arabia

${ }^{2}$ Center of Excellence in Biotechnology, King Saud University, Riyadh 11451, Kingdom of Saudi Arabia

Full list of author information is available at the end of the article
}

well as the waist-hip ratio (WHR), are two of the most commonly used non-invasive biomarkers of obesity.

While BMI remains the most popular obesity measure, its main disadvantage and limitation over waist circumference and WHR is that it does not take into account body fat distribution, a major predisposing factor to metabolic abnormalities. However, a novel anthropometric index that can rival WHR and waist circumference in clinical risk assessment is the sagittal abdominal diameter (SAD), considered a reliable surrogate measure of visceral abdominal fat, the fat tissue type that is significantly associated with cardiometabolic risk variables such as obesity, dyslipidemia and hypertension [6-8], measured non-invasively by a simple caliper [9].

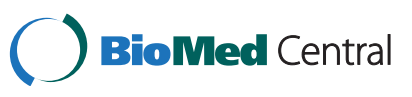


While several reports have suggested that SAD is a superior correlate of MetS criteria and insulin resistance than waist circumference, there has been little incorporation of this measure into routine clinical practice [10-12]. Furthermore, SAD was recently suggested to be superior to waist circumference in predicting dyslipidemia and hyperglycemia, at least in overweight adults [13]. The latter, measured at the level of the umbilicus, is modestly associated with coronary heart disease and visceral fat in males, at least in adults $[4,14]$. To date, very few studies have correlated SAD to other metabolic abnormalities, especially in children. Furthermore, very few studies have examined whether SAD in children and adolescents is superior to other anthropometric parameters in predicting cardiometabolic risk factors, particularly in this peninsula where increased prevalence of MetS and chronic diseases have been observed in both children and adults [15-17]. Thus, the present study aims to determine the superior marker of obesity through comparisons of SAD, BMI, WHR in terms of association strength with metabolic risk factors and levels of circulating adipocytokines in a cohort of Saudi children.

\section{Methods}

A total of 948 (495 male and 453 female) Saudi children aged between 10 and 17 years, were randomly selected from the existing database of the Biomarkers Screening in Riyadh Program (RIYADH Cohort), a capital-wide study composed of randomly selected individuals from different Primary Health Care Centers (PHCCs) in Riyadh, KSA. Ethical approval was granted by the Ethics Committee of the College of Science Research Center, King Saud University (KSU), Riyadh, KSA. Written consent was obtained after study orientation. The study was carried out at the Biomarkers Research Program, KSU, Riyadh, KSA. A questionnaire focusing on demographic information and past medical history was given to all participating subjects. Children with acute comorbidities that needed immediate medical attention were excluded from the study. MetS components were defined according to International Diabetes Federation (IDF) criteria [18].

\section{Anthropometry}

Anthropometry included height (to the nearest $0.5 \mathrm{~cm}$ ) and weight (to the nearest $0.1 \mathrm{~kg}$ ), as well as waist and hip circumferences utilizing a standardized measuring tape in $\mathrm{cm}$. The Holtain Khan abdominal caliper by Holtain Ltd (Crymych, UK) was used to measure SAD as previously described [19]. In brief, each subject was examined supine on a firm examination table. Using sliding calipers with parallel blades a direct reading can be made between its lower arm (touching the subject's back) and its sliding upper arm (touching the front of the subjects abdomen). BMI was calculated as $\mathrm{kg} / \mathrm{m} 2$ and systolic and diastolic blood pressure measurements were obtained. The definition of BMI-based obesity employed is gender and age specific as proposed by Cole and colleagues [20], which provides cut off points for body mass index in childhood that was based on international survey and linked to the widely accepted adult cut-off points for overweight and obesity (BMI of 25 and $30 \mathrm{~kg} / \mathrm{m}^{2}$, respectively).

\section{Blood chemistry}

Participating subjects were requested to return to their respective PHCCs after an overnight fast for anthropometry and blood withdrawal. Blood was transferred immediately to a non-heparinized tube for centrifugation. Serum was then transferred to a pre-labeled plain tube, stored in ice, and delivered to the Biomarkers Research Program in KSU on the same day. Fasting serum samples were stored in a $-20{ }^{\circ} \mathrm{C}$ freezer until analysis. Fasting glucose (FG) and lipid profile were measured using a chemical analyzer (Konelab, Vantaa, Finland). Serum leptin, adiponectin, resistin, insulin, TNF- $\alpha$ and aPAI-1 were measured using a Luminex instrument (Linco Research Inc., USA). The intra- and inter-assay variations were $1.4-7.9 \%$ and $<21 \%$, respectively for the above mentioned parameters measured using Luminex multiplex assay. Minimum detectable concentrations (MDC) were: leptin, $85.4 \mathrm{pg} / \mathrm{ml}$; adiponectin, $145.4 \mathrm{pg} / \mathrm{ml}$; resistin, $6.7 \mathrm{pg} / \mathrm{ml}$; insulin, $50.9 \mathrm{pg} / \mathrm{ml}$; TNF- $\alpha, 0.14 \mathrm{pg} / \mathrm{ml}$, and aPAI-1, $1.3 \mathrm{pg} / \mathrm{ml}$. hsC-reactive protein was determined using enzyme-linked immunosorbent assays (ELISA) (Immunodiagnoztik AG, Germany) with an intra- and inter-assay variations of $5.5-6.0 \%$ and $11.6-13.8 \%$, respectively. Serum angiotensin II was measured using human angiotensin II EIA kit (Phoenix pharmaceuticals, Belmont, CA, USA), (MDC $13 \mathrm{pg} / \mathrm{ml}$; linear range $13-240 \mathrm{pg} / \mathrm{ml}$ ) with intra- and inter-assay variations of $5.0-10.0 \%$ and $<15.0 \%$, respectively. Homeostasis model assessment of insulin resistance (HOMA-IR) was calculated as fasting insulin $(\mu \mathrm{U} / \mathrm{mL})$ times fasting glucose $(\mathrm{mmol} / \mathrm{L}) / 22.5$.

\section{Statistical analyses}

Data were analyzed using the Statistical Package for the Social Sciences (SPSS for Windows, version 11.5). Data were expressed as mean plus/minus standard error. Group comparisons were done using one way Analysis of Co-variance (ANCOVA), with age and gender as covariates, and Bonferroni analysis post-hoc. Frequencies were expressed as percent (\%). Partial (adjusted for age and gender) and bivariate (raw, unadjusted) correlation coefficients were determined and regression analysis was done to determine relations between variables of interest. Area under the curve (AUC) was done to 
reveal strength of associations elicited. $P$-values less than 0.05 were accepted to indicate statistically significant differences.

\section{Results}

Table 1 shows the basic characteristics of subjects. The over-all prevalence of childhood obesity in this cohort was $11.7 \%$. Figure 1 shows the positive linear trend between SAD and age in both boys and girls as well as the mean SAD across ages. Mean SAD for girls reach a growth peak from ages 12-14, where the difference between boys is at its maximum, and starts to plateau at 15 years. Mean SAD for boys on the other hand starts to increase at 13 years of age and continues to rise modestly until 16 years (Figure 1).

Table 1 General characteristics of the study population

\begin{tabular}{ll}
\hline Parameters & \\
\hline N & 948 \\
Age (years) & $13.7 \pm 2.2$ \\
Obese (\%) & 11.7 \\
Overweight (\%) & 16.7 \\
Gender (Male/Female) (\%) & $52.2 / 47.8$ \\
Body Mass Index (kg/m²) & $22.1 \pm 6.3$ \\
BMl z-score & $0.001^{*} 10^{-13} \pm 1.0$ \\
Waist circumference (cm) & $77.1 \pm 20.5$ \\
Hip circumference (cm) & $86.4 \pm 19.8$ \\
Waist-Hip Ratio & $0.91 \pm 0.33$ \\
Sagittal Abdominal Diameter (cm) & $17.4 \pm 5.4$ \\
Sagittal Abdominal Diameter z-score & $0.18 \pm 0.67$ \\
Systolic Blood Pressure (mmHg) & $106.4 \pm 10.6$ \\
Diastolic Blood Pressure (mmHg) & $69.5 \pm 7.8$ \\
Glucose (mmol/l) & $5.1 \pm 1.3$ \\
Insulin (ng/ml) & $11.2 \pm 1.2$ \\
HOMA-IR & $2.6 \pm 0.28$ \\
Triglycerides (mmol/l) & $1.1 \pm 0.60$ \\
Total Cholesterol (mmol/l) & $4.2 \pm 0.85$ \\
LDL-Cholesterol (mmol/l) & $2.7 \pm 0.76$ \\
HDL-Cholesterol (mmol/l) & $1.1 \pm 0.35$ \\
Leptin (ng/ml) & $15.7 \pm 2.8$ \\
Adiponectin ( $\mathrm{mg} / \mathrm{ml})$ & $20.4 \pm 1.4$ \\
Resistin (ng/ml) & $18.6 \pm 1.7$ \\
ANG II (ng/ml) & $0.67 \pm 0.05$ \\
aPAl-1 (ng/ml) & $19.8 \pm 2.4$ \\
C-Reactive Protein ( $\mathrm{mg} / \mathrm{ml})$ & $0.83(2.8)$ \\
TNF-a (pg/ml) & $8.6 \pm 1.0$ \\
\hline
\end{tabular}

Note: Data represented by Mean \pm Standard Error; CRP in median and inter-quartile range.
Bivariate and partial correlations between anthropometric indices and components of the metabolic syndrome, as well as inflammatory markers and adipocytokines are shown in Table 2. Bivariate associations of SAD showed significant associations to 12 out of 16 parameters examined; however, only blood pressure, triglycerides, HDL-cholesterol, leptin, resistin and aPAI-1 remained significant after adjusting for gender and age. BMI z-score on the other hand, had the highest number of significant associations, and retained blood pressure, lipids, glucose, and leptin after adjustment for age and gender. Finally, for WHR, only lipids (triglycerides, LDL- and total cholesterol), ANG II, as well as HOMA-IR remained significant after adjustment.

The area under the curve (AUCs) of various indices and metabolic risk components are summarized in Table 3. BMI z-score showed significance in all parameters measured with the exception of systolic blood pressure. SAD was a significant predictor of most other parameters, with the exception of systolic blood pressure and triglycerides. Lastly, waist-hip ratio was significant in glucose, 2 or more components of MetS and MetS itself.

\section{Discussion}

The main finding of the present cross-sectional study is that BMI was superior to both SAD and WHR in terms of significant associations to cardiometabolic parameters in children. SAD was no better than BMI, despite significant correlations with MetS components, insulin sensitivity indices and adipocytokine concentrations. Earlier studies done among children of European and Turkish descent showed that BMI was a better predictor of WHR and skin folds, respectively, with SAD values reported only as a correlate to BMI among European children [21,22].

Our findings however, differ from other ethnic groups, as waist circumference is more powerful in assessing metabolic disorders over other anthropometric values including SAD among Far Eastern children [23].

Our findings show that BMI is the best predictor of cardiometabolic risk factors as compared to SAD and WHR in children. With SAD however, some associations with cardiometabolic parameters remained significant even after adjustment for gender and age, notably blood pressure, triglycerides, and HDL-cholesterol. SAD also had more significant associations than BMI with regards to the adipocytokines suggesting that SAD may have a different predictive value independent of cardiometabolic risk factors. With the exception of HOMA-IR, these associations were not elicited with WHR. Furthermore, in terms of identifying adult patients with MetS, $\mathrm{SAD}$, in the absence of imaging techniques, has a sensitivity of $91 \%$ and specificity of $80 \%$ in patients at risk for 


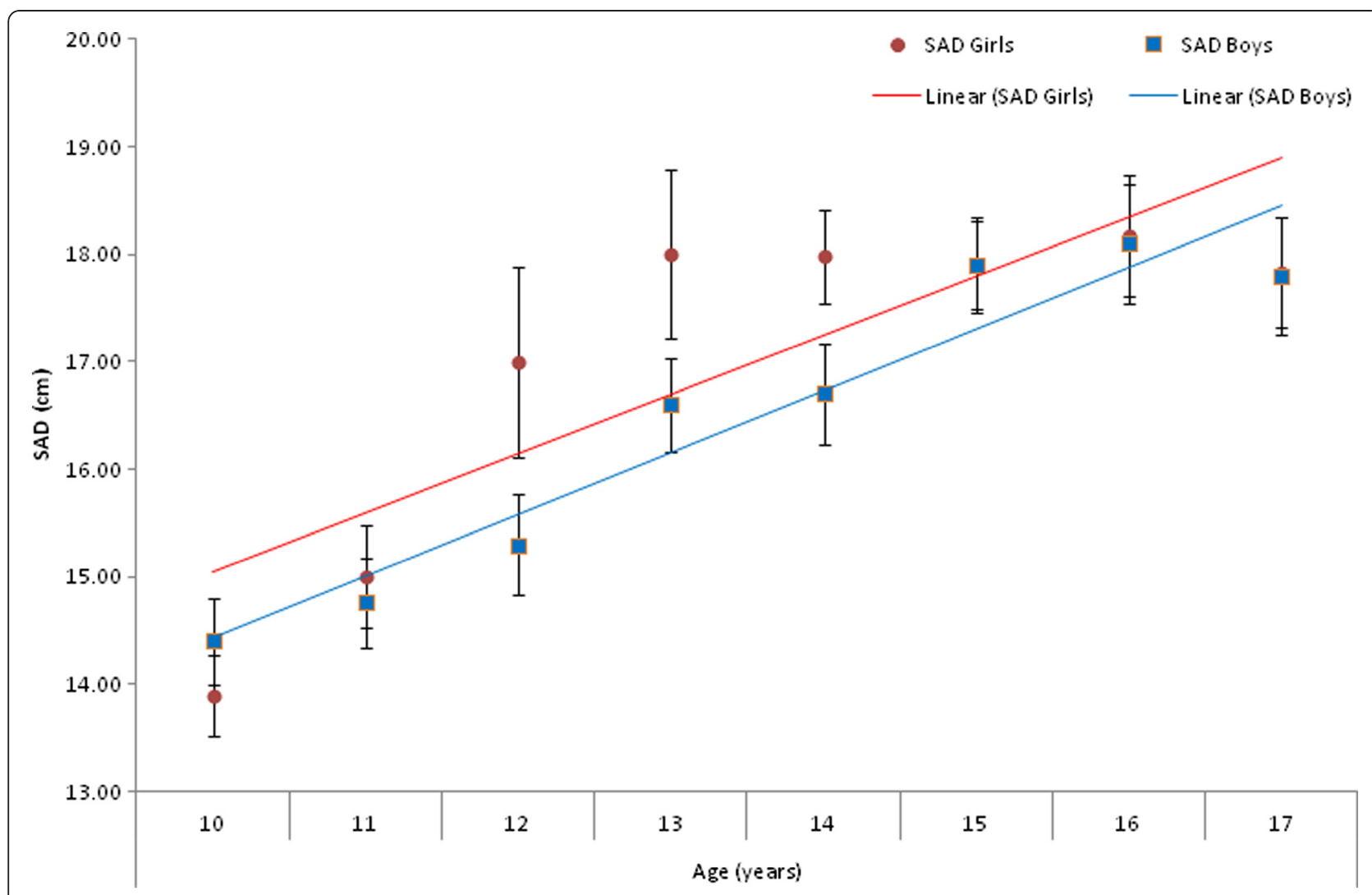

Figure 1 Linear trend between sagittal abdominal diameter in varying age groups in both boys and girls.

Table 2 Bivariate (Unadjusted) and partial (Controlled for Gender and Age) correlations of BMI, WHR and SAD to anthropometric and metabolic parameters

\begin{tabular}{|c|c|c|c|c|c|c|}
\hline \multirow[t]{2}{*}{ PARAMETERS } & \multicolumn{2}{|c|}{ BMI z-score } & \multicolumn{2}{|l|}{ WHR } & \multicolumn{2}{|c|}{ SAD z-score } \\
\hline & Bivariate & Partial & Bivariate & Partial & Bivariate & Partial \\
\hline Systolic Blood Pressure $(\mathrm{mmHg})$ & $0.40 * *$ & $0.19 * *$ & 0.11 & -0.03 & $0.32 * *$ & $0.20 * *$ \\
\hline Diastolic Blood Pressure (mmHg) & $0.29 * *$ & $0.18 * *$ & -0.01 & -0.03 & $0.25 * *$ & $0.16 * *$ \\
\hline Glucose $(\mathrm{mmol} / \mathrm{l})$ & $0.19 * *$ & $0.18 * *$ & $0.07 *$ & 0.06 & $0.09 * *$ & 0.02 \\
\hline Insulin (IU/ml) & $0.52 * *$ & -0.01 & $0.17 *$ & 0.10 & $0.38 * *$ & -0.10 \\
\hline HOMA-IR & $0.52 * *$ & -0.01 & $0.21 * *$ & $0.12 *$ & $0.36 * *$ & -0.10 \\
\hline Triglycerides (mmol/l) & $0.30 * *$ & $0.21 * *$ & $0.11 *$ & $0.23 * *$ & $0.17 * *$ & $0.08 *$ \\
\hline Total Cholesterol (mmol/l) & $0.13 * *$ & $0.14 * *$ & -0.02 & $-0.11 *$ & $0.08 *$ & 0.02 \\
\hline LDL-Cholesterol (mmol/l) & $0.17 * *$ & $0.17^{* *}$ & -0.04 & $-0.24 * *$ & 0.11 & 0.06 \\
\hline HDL-Cholesterol (mmol/l) & $-0.25 * *$ & $-0.19 * *$ & -0.04 & 0.09 & $-0.20 * *$ & $-0.14 * *$ \\
\hline Leptin (ng/ml) & $0.49 * *$ & $0.34 * *$ & 0.04 & 0.01 & $0.35 * *$ & $0.22 * *$ \\
\hline Adiponectin ( $\mu \mathrm{g} / \mathrm{ml})$ & $-0.25 * *$ & -0.14 & -0.14 & 0.00 & $-0.20 * *$ & -0.16 \\
\hline Resistin (ng/ml) & $0.18 * *$ & 0.12 & $-0.11 * *$ & -0.08 & $0.18 * *$ & $0.07 *$ \\
\hline ANG II (ng/ml) & 0.04 & -0.01 & 0.07 & $0.15 *$ & -0.03 & 0.02 \\
\hline aPAl-1 (ng/ml) & $0.13 * *$ & 0.14 & 0.02 & -0.00 & $0.10 * *$ & $0.10 * *$ \\
\hline C-Reactive Protein $(\mu \mathrm{g} / \mathrm{ml})$ & 0.04 & 0.05 & 0.06 & -0.06 & 0.02 & 0.12 \\
\hline TNF-a (pg/ml) & -0.03 & -0.50 & -0.04 & -0.42 & -0.02 & -0.31 \\
\hline
\end{tabular}

Note: Data presented as coefficients (R); ${ }^{*}$ denotes $p$-value $<0.05$ level; ** denotes $p$-value $<0.01$ level. 
Table 3 Areas under ROC curve (AUC) of various anthropometric indices and metS risk factors

\begin{tabular}{|c|c|c|c|c|}
\hline Test Variable & $\begin{array}{l}\text { Anthropometric } \\
\text { Parameter }\end{array}$ & $\mathrm{AUC} \pm \mathrm{SE}$ & $\begin{array}{l}\text { Asymptotic } \\
\text { Significance }\end{array}$ & $\begin{array}{l}95 \% \\
\text { Confidence } \\
\text { Interval }\end{array}$ \\
\hline \multirow[t]{3}{*}{ Systolic Blood Pressure } & BMl z-score & $0.526 \pm 0.040$ & 0.926 & $(0.447,0.605)$ \\
\hline & WHR & $0.513 \pm 0.001$ & 0.094 & $(0.005,0.031)$ \\
\hline & SAD z-score & $0.539 \pm 0.048$ & 0.893 & $(0.445,0.633)$ \\
\hline \multirow[t]{3}{*}{ Triglycerides } & BMI z-score & $0.721 \pm 0.065$ & 0.010 & $(0.594,0.848)$ \\
\hline & WHR & $0.662 \pm 0.069$ & 0.060 & $(0.527,0.798)$ \\
\hline & SAD z-score & $0.634 \pm 0.080$ & 0.119 & $(0.477,0.792)$ \\
\hline \multirow[t]{3}{*}{ HDL-Cholesterol } & BMI z-score & $0.623 \pm 0.019$ & $<0.001$ & $(0.583,0.660)$ \\
\hline & WHR & $0.535 \pm 0.020$ & 0.070 & $(0.497,0.574)$ \\
\hline & SAD z-score & $0.599 \pm 0.019$ & $<0.001$ & $(0.561,0.636)$ \\
\hline \multirow[t]{3}{*}{ Glucose } & BMl z-score & $0.615 \pm 0.024$ & $<0.001$ & $(0.567,0.662)$ \\
\hline & WHR & $0.563 \pm 0.025$ & 0.012 & $(0.515,0.612)$ \\
\hline & SAD z-score & $0.554 \pm 0.026$ & 0.031 & $(0.504,0.604)$ \\
\hline \multirow{3}{*}{$\begin{array}{l}2 \text { or more IDF MetS } \\
\text { Components }\end{array}$} & BMI z-score & $0.777 \pm 0.016$ & $<0.001$ & $(0.747,0.808)$ \\
\hline & WHR & $0.641 \pm 0.019$ & $<0.001$ & $(0.605,0.678)$ \\
\hline & SAD z-score & $0.678 \pm 0.019$ & $<0.001$ & $(0.641,0.714)$ \\
\hline \multirow[t]{3}{*}{ IDF MetS } & BMI z-score & $0.776 \pm 0.025$ & $<0.001$ & $(0.727,0.825)$ \\
\hline & WHR & $0.632 \pm 0.025$ & $<0.001$ & $(0.582,0.681)$ \\
\hline & SAD z-score & $0.693 \pm 0.029$ & $<0.001$ & $(0.636,0.750)$ \\
\hline
\end{tabular}

Note: Significant at $p<0.05$.

cardiovascular events [24], and even more superior in assessing cardiovascular risk among the severely obese [25]. It is noted however that the predictive utility of SAD among normal adults, and in this case, children, will be clearly less as compared to those who harbor known CVD risk factors such as obesity. In the present study, the significant influence of SAD on the expression of numerous adipocytokines makes it a better measure than WHR, but not as good as BMI, in assessing cardiometabolic risk profile in children. This is because when waist or hip circumference is measured in a standing person with an increased volume of intra-abdominal adipose tissue, all fat tissue is pulled towards gravity, and may therefore not be that accurate in assessing intraabdominal fat especially among children who are very obese. When the same person lies supine the fat mass shifts cranially, causing anterior projection of the abdomen (abdominal height) which is measured by the SAD [19]. It is the antero-posterior fat that seems to be important for the prediction of the MetS. The persistence of significant associations of lipids and selected adipocytokines with SAD agrees with the findings of several cross-sectional observations that SAD is the surrogate marker for visceral fat as compared to waist circumference [26,27].

The authors acknowledge some limitations. The crosssectional nature of the study limits our findings to observations and only prospective longitudinal studies can confirm whether the persistence of these associations translate into increased odds of developing chronic diseases. Pubertal status was also not assessed and this could have affected the results, since BMI, waist circumference, SAD and MetS itself can also be influenced by the developmental trajectories and hormonal changes occurring during adolescence, and excess adiposity during childhood could advance puberty in girls and delay onset in boys [28]. Finally, the results cannot be generalized, as it may differ if applied to children of other ethnicities.

\section{Conclusion}

In conclusion, while SAD is significantly associated with several components of MetS, including adipcytokines in Arab children and adolescents, it is not superior to BMI in terms of association strength. The use of SAD, therefore, may not be clinically practical for routine use as compared to BMI, at least among children, but is more useful clinically when compared to waist-hip ratio. Prospective longitudinal studies are suggested to compare its causal association with harder endpoints such as early onset diabetes and cardiovascular disease.

Competing interests

The authors declare that they have no competing interests. 


\section{Authors' contributions}

OSA and NMA conceived and carried out the study. MSA and KA participated in the design, subject recruitments and data collection. HD and SY carried out sample analysis. SLS and GPC performed statistical analysis and drafted the final version of the manuscript. All authors approved and read the final manuscript.

\section{Acknowledgments}

This study was generously funded by National Plan for Science and Technology (NPST), (08-MED-614-02) Riyadh, Saudi Arabia. The authors thank Mr. Benjamin Vinodson and Mr. Saim Ulhaq for the statistical analyses of the data.

\section{Author details}

${ }^{1}$ Biomarkers Research Program, Biochemistry Department, College of Science, King Saud University, Riyadh 11451, Kingdom of Saudi Arabia. ${ }^{2}$ Center of Excellence in Biotechnology, King Saud University, Riyadh 11451, Kingdom of Saudi Arabia. ${ }^{3}$ Clinical Pharmacy Department, College of Pharmacy, King Saud University, Riyadh 11451, Kingdom of Saudi Arabia. ${ }^{4}$ Department of Biochemistry, National Research Centre, Cairo 12311, Egypt. ${ }^{5}$ First Department of Pediatrics, Athens University Medical School, Athens 11527, Greece.

Received: 31 December 2011 Accepted: 31 July 2012

Published: 7 August 2012

\section{References}

1. Larsson I: Human body composition: Reference data and anthropometric equations, the metabolic syndrome and risk. Intellecta Docusys $A B$ Vastra Frolunda 2005, 91(628):6508-0.

2. Vague J: The degree of masculine differentiation of obesities: a risk factor for determining predisposition to diabetes, atherosclerosis, gout, and uric calculous disease. Am J Clin Nutr 1956, 4:20-34

3. Canoy D, Boekholdt SM, Wareham N, Luben R, Welch A, Bingham S, Buchan I, Day N, Khaw KT: Body fat distribution and risk of coronary heart disease in men and women in the European prospective investigation into cancer and nutrition in Norfolk cohort: a population-based prospective study. Circulation 2007, 11:2933-2943.

4. Rexrode KM, Buring JE, Manson JE: Abdominal and total adiposity and risk of coronary heart disease in men. Int. J. Obes. Relat. Metab. Disord. 2001 25:1047-1056.

5. Rexrode KM, Carey VJ, Hennekens CH, Walters EE, Colditz GA, Stampfer MJ, Willett WC, Manson JE: Abdominal adiposity and coronary heart disease in women. JAMA 1998, 280:1843-1848.

6. Gustat J, Elkasabany A, Srinivasan S, Berenson GS: Relation of abdominal height to cardiovascular risk factors in young adults: the bogalusa heart study. Am J Epidemiol 2000, 151:885-1891.

7. Ivkovic-Lazar T: Current diagnostic methods of the specific distribution of adipose tissue. Med. Pregl. 2000, 53:584-587.

8. Sampaio LR, Simoes EJ, Assis AM, Ramos LR: Validity and reliability of the sagittal abdominal diameter as a predictor of visceral abdominal fat. Arq. Bras. Endocrinol. Metabol. 2007, 51:980-986.

9. Mukuddem-Petersen J, Snijder MB, van Dam RM, Dekker JM, Bouter LM, Stehouwer CD, Heine RJ, Nippels G, Seidell JC: Sagittal abdominal diameter: no advantage compared with other anthropometric measures as a correlate of components of the metabolic syndrome in elderly from the hoorn study. Am J Clin Nutr 2006, 84:995-1002.

10. Petersson H, Daryani A, Riserus U: Sagittal abdominal diameter as a marker of inflammation and insulin resistance among immigrant women from the Middle East and native Swedish women: a cross-sectional study. Cardiovasc Diabetol 2007, 6:10.

11. Anjana M, Sandeep S, Deepa R, Vimaleswaran KS, Farooq S, Mohan V: Visceral and central abdominal fat and anthropometry in relation to diabetes in Asian Indians. Diabetes Care 2004, 27:2948-2953.

12. Oppert JM, Charles MA, Thibult N, Guy-Grand B, Eschwege E, Ducimetierre P: Anthropometric estimates of muscle and fat mass in relation to cardiac and cancer mortality in men: the Paris prospective study. Am J Clin Nutr 2002, 75:1107-1113.

13. Pimentel GD, Moreto F, Takahashi MM, Portero-McLellan KC, Burini RC. Sagital abdominal diameter, but not waist circumference is strongly associated with glycemia, triacilglycerols and HDL-C levels in overweight adults. Nutr Hosp 2011, 26:1125-1129.

14. Van Der Kooy K, Leenen R, Seidell JC, Deurenberg P, Visser M: Abdominal diameters as indicators of visceral fat; comparison between magnetic resonance imaging and anthropometry. Br J Nutr 1993, 70:47-58.

15. Al-Daghri NM: Extremely high prevalence of metabolic syndrome manifestations among Arab youth: A call for early intervention. Eur. J. Clin. Invest. 2010, 40:1063-1066.

16. Al-Daghri NM, Al-Attas OS, Alokail MS, Alkharfy KM, Sabico S, Chrousos GP: Decreasing prevalence of the full metabolic syndrome but a persistently high prevalence of dyslipidemia among adult urban Saudis. PLoS One 2010, 5:e12159.

17. Al-Daghri NM, Al-Attas OS, Alokail MS, Alkharfy KM, Sabico SLS, Chrousos GP: Diabetes mellitus type 2 and other chronic non-communicable diseases in the Central Region, Saudi Arabia (Riyadh Cohort 2): A decade of an epidemic. BMC Med. 2011, 9:76.

18. Zimmet P, Alberti G, Kaufman F, Tajima N, Silink M, Arslanian S, Wong G, Bennett P, Shaw J, Caprio S: International diabetes federation task force on epidemiology and prevention of diabetes; The metabolic syndrome in children and adults. Lancet 2007, 369:2059-2061.

19. Al-Daghri N, Alokail M, Al-Attas O, Sabico S, Kumar S: Establishing abdominal height cut-offs and their association with conventional indices of obesity among Arab children and adolescents. Ann. Saudi Med. 2010, 30:209-214.

20. Cole TJ, Bellizzi MC, Flegal KM, Dietz WH: Establishing a standard definition for child overweight and obesity worldwide: international survey. BMJ 2000, 320:1240-1246.

21. Larsson C, Hernell O, Lind T: Moderately elevated body mass index is associated with metabolic variables and cardiovascular risk factors in Swedish children. Acta Paediatr. 2011, 100:102-108.

22. Agirbasli M, Agaoglu NB, Ergonul O, Yagmur I, Aydogar H, Oneri T, Ozturk O: Comparison of anthropometric indices in predicting metabolic syndrome components in children. Metab Syndr Relat Disord 2011, 9:453-469.

23. Chuang SY, Pan WH: Predictability and implications of anthropometric indices for metabolic abnormalities in children: nutrition and health survey in Taiwan elementary children, 2001-2002. Asia Pac. J. Clin. Nutr. 2009, 18:272-279.

24. Hoenig MR: MRI sagittal abdominal diameter is a stronger predictor of metabolic syndrome than visceral fat area or waist circumference in a high risk vascular cohort. Vasc. Health Risk Manag. 2010, 6:629-633.

25. Guzzaloni G, Minocci A, Marzullo P, Liuzzi A: Sagittal abdominal diameter is more predictive of cardiovascular risk than abdominal fat compartments in severe obesity. Int. J. Obes. (Lond) 2009, 33:233-238.

26. Asayama K, Dobashi K, Hayashibe H, Kodera K, Uchida N, Nakane T, Araki T, Nakazawa S: Threshold values of visceral fat measures and their anthropometric alternatives for metabolic derangement in Japanese obese boys. Int. J. Obes. Relat. Metab. Disord. 2002, 26:208-213.

27. Pimental GD, Moreto F, Takahashi MM, Portero-McLellan KC, Burini RC: Sagital abdominal diameter, but not waist circumference is strongly associated with glycemia, triacilglycerols and HDL-C levels in overweight adults. Nutr Hosp 2011, 26:1125-1129.

28. Burt Solorzano CM, McCartney CR: Obesity and the pubertal transition in girls and boys. Reproduction 2010, 140:399-410

doi:10.1186/1471-2431-12-119

Cite this article as: Al-Attas et al: Association of body mass index, sagittal abdominal diameter and waist-hip ratio with cardiometabolic risk factors and adipocytokines in Arab children and adolescents. BMC Pediatrics 2012 12:119. 